Nzeusseu Toukap, F.A. Houssiau for fruitful discussions and/or contribution to recruitment.

Disclosure of Interest: None declared

DOI: 10.1136/annrheumdis-2017-eular.2387

\section{OP0284 EVALUATION OF THE IMPACT OF BASELINE LEVELS OF MRI-DETECTED INFLAMMATION ON TREATMENT RESPONSE IN EARLY, SEROPOSITIVE, MTX-NAÏVE RA: DATA FROM THE AVERT TRIAL}

$\underline{\text { H. Ahmad }}^{1}$, J. Baker ${ }^{2}$, M. Østergaard ${ }^{3}$, P. Emery ${ }^{4}$, P. Durez ${ }^{5}$, J. Ye $^{1}$, S. Banerjee ${ }^{1}$, P. Conaghan ${ }^{6} .{ }^{1}$ Bristol-Myers Squibb, Princeton; ${ }^{2}$ University of Pennsylvania, Philadelphia, United States; ${ }^{3}$ Rigshospitalet, University of Copenhagen, Copenhagen, Denmark; ${ }^{4}$ University of Leeds and Leeds Musculoskeletal Biomedical Research Unit, Leeds, United Kingdom; ${ }^{5}$ Université Catholique de Louvain, Brussels, Belgium; ${ }^{6}$ University of Leeds, Leeds, United Kingdom

Background: AVERT (Assessing Very Early Rheumatoid arthritis Treatment) was a Phase IIlb, randomized, 24-month (M) trial with a 12M, double-blind treatment period, and included contrast-enhanced MRI of the dominant hand and wrist. MRI can provide direct evidence of joint inflammation, enabling stratification of patient (pt) data according to MRI inflammation level, e.g. low vs high. ${ }^{1}$ This stratification is hypothesized to predict clinical treatment response.

Objectives: To evaluate the proportion of pts achieving remission at M12 by baseline (BL) MRI-detected inflammation status and treatment group.

Methods: In AVERT, pts with early RA received abatacept (ABA) + MTX, ABA monotherapy or MTX. MRI inflammation was scored by two central readers at BL and M12. In this post hoc analysis, pts were stratified into "low" and "high" BL MRI inflammation groups. Low: $\leq 3$ for synovitis, $\leq 3$ for osteitis and $\leq 9$ when combined (osteitis double weighted) $;^{2}$ high: $>3,>3$ or $>9$, respectively. The proportion of pts achieving CDAI $(\leq 2.8)$, DAS28 (CRP; $<2.6)$, SDAI $(\leq 3.3)$ and Boolean (TJC $\leq 1, \mathrm{SJC} \leq 1, \mathrm{CRP} \leq 1 \mathrm{mg} / \mathrm{dL}$ and pt global assessment of disease activity $\leq 1$ [0-10 cm scale]) remission at M12 was compared by BL MRI inflammation and treatment group.

Results: Of 351 pts randomized and treated, $337(96.0 \%)$ had MRI data at BL (ABA + MTX, $n=114$; ABA monotherapy, $n=112$; MTX, $n=111$ ). Mean (SD) BL synovitis, osteitis and total scores, respectively, for pts with low MRI inflammation receiving ABA + MTX vs MTX alone were: 2.6 (2.0) vs $3.1(2.4), 0.3$ (0.6) vs 0.2 (0.5) and 3.1 (2.4) vs 3.5 (2.7); high MRI inflammation: 9.2 (3.6) vs 9.3 (3.6), 10.0 (9.7) vs 10.7 (9.8) and 29.3 (21.3) vs 30.7 (21.3). BL DAS28 (CRP), CDAI and SDAl scores, respectively, for pts with low MRI inflammation receiving ABA + MTX vs MTX alone were: 5.1 (1.1) vs $5.0(1.3), 34.0(14.7)$ vs $32.1(15.0)$ and 39.9 (17.4) vs 43.5 (24.6); high MRI inflammation: 6.2 (1.2) vs 5.6 (1.4), 43.4 (16.2) vs 37.7 (18.1) and 76.9 (44.9) vs 61.1 (35.2). The proportion of pts with low BL MRI inflammation attaining remission at $\mathrm{M} 12$ was similar regardless of treatment. In pts with high MRI inflammation, remission rates were significantly greater in pts treated with ABA + MTX vs MTX alone (Table).

Table 1. Proportion of Patients in Remission at Month 12 by Treatment and Baseline MRI Inflammation Status*

\begin{tabular}{lcccccc}
\hline Remission criteria & \multicolumn{2}{c}{ Low MRI inflammation } & & \multicolumn{2}{c}{ High MRI inflammation } \\
\cline { 2 - 3 } & ABA+MTX $(\mathrm{n}=63)$ & $\mathrm{MTX}(\mathrm{n}=62)$ & & ABA+MTX $(\mathrm{n}=51)$ & MTX $(\mathrm{n}=49)$ \\
\hline DAS28 (CRP) & $39(61.9)$ & $31(50.0)$ & & $31(60.8)^{\dagger}$ & $20(40.8)$ \\
CDAI & $24(38.1)$ & $20(32.3)$ & & $24(47.1)^{\dagger}$ & $10(20.4)$ \\
SDAl & $25(39.7)$ & $20(32.3)$ & & $23(45.1)^{\dagger}$ & $8(16.3)$ \\
Boolean & $22(34.9)$ & $18(29.0)$ & & $20(39.2)^{\dagger}$ & $8(16.3)$ \\
\hline
\end{tabular}

Data are $\mathrm{n}(\%)$; *low: $\leq 3$ synovitis, $\leq 3$ osteitis and $\leq 9$ combined (osteitis double weighted); high: $>3,>3$ or $>9 ;{ }^{\dagger} p<0.05$ vs MTX alone.

Conclusions: Pts with higher MRI inflammation may derive greater benefit from abatacept + MTX vs MTX alone. BL MRI inflammation is a predictor of subsequent clinical treatment response to abatacept in RA. MRI may have clinical utility in treatment decisions beyond information obtained from clinical assessments alone. References:

[1] Gandjbakhch F, et al. J Rheumatol 2014;41:398-406.

[2] Ahmad HA, et al. Ann Rheum Dis 2016;75:624.

Disclosure of Interest: H. Ahmad Shareholder of: Bristol-Myers Squibb, Employee of: Bristol-Myers Squibb, J. Baker: None declared, M. Østergaard Grant/research support from: AbbVie, Bristol-Myers Squibb, Janssen, Merck, Speakers bureau: AbbVie, Bristol-Myers Squibb, Boehringer Ingelheim, Celgene, Eli Lilly, Centocor, GSK, Hospira, Janssen, Merck, Mundipharma, Novartis, Novo Nordisk, Orion, Pfizer, Regeneron, Schering-Plough, Roche, Takeda, UCB, Wyeth, P. Emery Grant/research support from: AbbVie, Merck, Pfizer, Roche, Consultant for: AbbVie, Bristol-Myers Squibb, Merck, Pfizer, Roche, Lilly, Novartis, Samsung Bioepis, P. Durez Speakers bureau: Bristol-Myers Squibb, Lilly, Janssen, Sanofi, Roche, Pfizer, J. Ye Shareholder of: Bristol-Myers Squibb, Employee of: BristolMyers Squibb, S. Banerjee Shareholder of: Bristol-Myers Squibb, Employee of: Bristol-Myers Squibb, P. Conaghan Grant/research support from: Bristol-Myers Squibb, Consultant for: AbbVie, Lilly, Novartis, Pfizer, Speakers bureau: AbbVie, Bristol-Myers Squibb, Roche

DOI: 10.1136/annrheumdis-2017-eular.1723

\section{OP0285 ATTENUATION OF FLUORINE-18-FLUORODEOXYGLUCOSE UPTAKE IN LARGE VESSEL GIANT CELL ARTERITIS AFTER SHORT-TERM HIGH-DOSE STEROID TREATMENT - A DIAGNOSTIC WINDOW OF OPPORTUNITY}

B.D. Nielsen ${ }^{1}$, L.C. Gormsen ${ }^{2}$, I.T. Hansen ${ }^{1}$, K.K. Keller ${ }^{1}$, P. Therkildsen ${ }^{1}$, E.-M. Hauge ${ }^{1} .{ }^{1}$ Department of Rheumatology; ${ }^{2}$ Department of Nuclear Medicine and PET centre, Aarhus University Hospital, Århus, Denmark

Background: Fluorine-18-fluorodeoxyglucose (FDG) PET/CT is increasingly used to diagnose large vessel GCA (LV-GCA) due to its excellent diagnostic accuracy[1]. However, PET/CT is not always readily available, which may compel the clinician to 1) either delay steroid treatment at the risk of GCA related complications, or 2) initiate treatment at the expense of diagnostic sensitivity of the FDG PET/CT study.

Objectives: To evaluate if FDG PET/CT can accurately diagnose LV-GCA after 3 or 10 days of high-dose steroid treatment.

Methods: Twenty-four treatment-naïve patients (16 women) with a mean age of 69 (range 57-84) years with FDG PET/CT (PET0) proven LV-GCA repeated FDG PET/CT after either 3 (PET3, $n=10$ ) or 10 days (PET10, $n=14)$ of treatment with oral prednisolone $60 \mathrm{mg}$ daily. Prior to treatment, clinical examination and laboratory tests were performed to confirm GCA and exclude differential diagnoses. A temporal artery biopsy (TAB) was performed in all patients.

Two experienced nuclear medicine physicians blinded to clinical data reviewed the FDG PET/CT images. LV-GCA was suspected if increased FDG uptake in the wall of the aorta and/or supra-aortic branches was observed. A semi-quantitative approach was applied (a.m. Meller) in which FDG uptake was graded on a 5-point scale $(0 ;$ no uptake, $1 ; \leq$ blood pool, $2 ;>$ blood pool, $\leq$ liver, $3 ;>$ liver, $4 ; \geq 2 x$ liver). A score $\geq 3$ was considered consistent with vasculitis[2]. Vascular composite scores (CS) was calculated summarizing grades from assessed vascular regions; Aortic: Aorta ascendens, aorta descendens and aortic arch; aortic branches: Vertebral, carotic and subclavian/axillary artery.

Results: Mean CRP and ESR were 72 (95\% Cl: 55; 94) mg/l and $81(95 \% \mathrm{Cl}$ : $72 ; 90) \mathrm{mm} / \mathrm{h}$, respectively. ACR criteria for GCA was fulfilled by $18 / 24$ patients and 17/21 had a positive TAB. Mean number of prednisolone doses before the post-treatment FDG PET/CT were 3.1 (SD 0.3) (PET3) and 10.3 (SD 0.7) (PET10).

Vascular CS in aorta did not decrease at PET3 (9 (IQR 9-9) vs. 9 (IQR 6-9)) whereas a significant decrease was observed in aortic branches at PET3 6.5 (IQR 6-8) vs 5.5 (IQR 5-7), p <0.01) and both vascular domains at PET10 (Aortic; 9 (IQR 9-9) vs. 5.5 (IQR 3-6), aortic branches; 7 (IQR 7-8) vs 5 (IQR 4-6)). Although, FDG uptake decreased in aortic branches after 3 days, LV-GCA could still be accurately diagnosed in 10/10 patients. By contrast, LV-GCA could only be diagnosed in $5 / 14$ patients after 10 days (PET0 vs. PET10, $p<0.01$ ).

At day 10, VAS global was significantly higher in patients with positive PET10 compared to patients with negative PET10 (5.2 (95\% Cl 3.6; 7.0) vs. 2.7 (95\% $\mathrm{Cl} 1.2 ; 4.2), \mathrm{p}<0.05)$. No clinically significant differences in baseline phenotypical presentation, CRP or PET CS were found between patients with positive and negative PET10, respectively.

Interrater reliability of visual FDG-uptake-grading was substantial (agreement 90\%, Cohens weighted kappa 0.67).

Conclusions: In LV-GCA, high-dose steroid treatment for three or ten days differentially attenuates the regional uptake of FDG but diagnostic accuracy remains within the first three days.

References:

[1] Puppo et al. BioMed research international 2014.

[2] Stellingwerff MD et al. Medicine 2015

Acknowledgements: Assesment of PET scans by Stine Kramer and Tronds Bogsrud is mostly appreciated.

Disclosure of Interest: None declared

DOI: 10.1136/annrheumdis-2017-eular.5788

\section{OP0286 THE UTILITY OF THE OMERACT ULTRASOUND TENOSYNOVITIS SCORING SYSTEM IN MULTICENTER CLINICAL TRIALS}

M. Ammitzbøll-Danielsen ${ }^{1,2}$, M. Østergaard ${ }^{1,2}, N$. Esperanza $^{3,4}$, A. lagnocco ${ }^{5}$, I. Möller ${ }^{6}$, M.-A. D'Agostino ${ }^{7}$, F. Gandjbakhch ${ }^{8}$, L. Terslev ${ }^{1}$. ${ }^{1}$ Copenhagen Center for Arthritis Research, Center for Rheumatology and Spine Diseases, Rigshospitalet, Glostrup; ${ }^{2}$ Department of Clinical Medicine, University of Copenhagen, Copenhagen, Denmark; ${ }^{3}$ Department of Rheumatology, Joint and Bone Research Unit. Hospital Universitario Fundación Jiménez Díaz;

${ }^{4}$ Department of Rheumatology, Hospital General Universitario Gregorio Marañón and Universidad Complutense, Madrid, Spain; ${ }^{5}$ Dipartimento Scienze Cliniche e Biologiche, Università degli Studi di Torino, Turin, Italy; ${ }^{6}$ Department of Rheumatology, Instituto Poal de Reumatología, Barcelona, Spain; ${ }^{7}$ Department of Rheumatology, Assistance publique-Hôpitaux de Paris Ambroise Paré Hospital, Boulogne-Billancourt, Université Versailles Saint Quentin en Yvelines; ${ }^{8}$ Department of Rheumatology, Praticien Hospitalier, Paris, France

Background: Tenosynovitis is very common in patients with rheumatoid arthritis (RA) and is associated with lower physical function. Several studies have confirmed the limitations of clinical examination for detection of tenosynovitis in comparison with ultrasound (US) and a highly validated and reliable US scoring 